\title{
A FUNÇÃO SOCIAL DA EMPRESA COMO FORMA DE PROTEÇÃO AO EMPREGADO
}

\section{THE SOCIAL FUNCTION OF THE COMPANY AS A FORM OF EMPLOYEE PROTECTION}

\section{LEONARDO JOSE PEIXOTO}

Doutor em Direito pela Universidade Federal do Ceará - UFC (2017). Mestre em Direito Constitucional pela Universidade de Fortaleza - UNIFOR (2010). Professor dos cursos de Graduação e Pós-Graduação Direito da Universidade de Fortaleza e do Centro Universitário Estácio do Ceará. Coordenador do Curso de Direito da Faculdade Vidal de Limoeiro - FAVILI. Sócio do Conselho Nacional de Pesquisa Pós-Graduação em Direito - CONPEDI. Presidente da Comissão de Estudo e Defesa da Concorrência da Ordem dos Advogados do Brasil, Seccional do Ceará - OAB/CE (2016-2018).Tem experiência na área de Direito, com ênfase em Direito Econômico, atuando principalmente nos seguintes temas: Análise econômica do Direito, Direito da Concorrência, Direito do Consumidor, Direito Industrial, Direito Empresarial, Políticas Públicas, Direito Processual Civil, Prática Cível e Métodos Adequados de Solução de Controvérsias.

\section{CINTHIA MONESES MAIA}

Especialista em Direito e Processo do Trabalho. Mestranda em Direito Privado pelo Centro Universitário 7 de Setembro (UNI7). cinthiamaia_@hotmail.com. Advogada.

\section{RESUMO}

O presente estudo tem como objetivo principal demonstrar que a função social da empresa pode ser utilizada como fundamento para proteção à parte hipossuficiente da relação trabalhista, o trabalhador. Desse modo, serão estudados alguns aspectos relativos a função social da propriedade e da empresa no segundo capítulo, fazendo 
um paralelo com o Direito do Trabalho. Logo após, serão analisadas questões específicas ao Direito do Trabalho, como sua origem e o princípio mais importante dessa disciplina, o princípio da proteção ao trabalhador. No último seguimento, serão examinadas as espécies de hipossuficiência a fim de demonstrar que a vulnerabilidade do empregador não é meramente econômica.

PALAVRAS-CHAVE: Função social; Empresa; Hipossuficiência; Trabalhador.

\section{ABSTRACT}

The main objective of this study is to demonstrate that the social function of company can be used as a basis for protecting the hyposufficient part of the labor relation, the worker. In this way, some aspects related to the social function of property and the company in the first chapter will be studied, paralleling with Labor Law. Subsequently, issues specific to Labor Law will be analyzed, as their origin and the most important principle of this discipline, the principle of worker protection. In the last chapter, the species of hyposufficiency will be examined in order to demonstrate that the vulnerability of the employer is not merely economic.

KEYWORDS: Social function; Company; Hypossuficience; Employee.

\section{INTRODUÇÃO}

Este estudo tem como objetivo principal demonstrar que a função social da empresa pode e deve ser utilizada como mais uma maneira de proteger a parte hipossuficiente da relação de trabalho, no caso, o trabalhador.

É cediço o fato de que as relações trabalhistas são compostas por uma parte detentora do poder, o empregador, e por outra mais frágil, o empregado. A relevância do estudo se funda no fato de que, raríssimas vezes, a função social da empresa é utilizada como um dos fundamentos para a proteção da parte hipossuficiente da demanda. Desse modo, busca-se demonstrar a relação entre a 
função social e a proteção ao trabalhador, de forma a fortalecer os argumentos de proteção ao trabalho e ao trabalhador.

Assim, a função social da empresa será examinada no segundo módulo, de tal maneira que restará claro o fato de ela advir do princípio da função social da propriedade e, também, que não pode ser vista, apenas, como uma simples limitação ao poder do proprietário e do empresário.

No terceiro segmento, serão estudados pontos referentes ao Direito do Trabalho, iniciando-se o capítulo com uma breve apresentação da história do Direito Laboral, o qual surge das lutas dos trabalhadores contra as situações degradantes em que se encontravam. Essa parte se faz necessária para que se possa compreender melhor o princípio da proteção e também a hipossuficiência do trabalhador.

Após o breve escorço histórico, será explorado o princípio da proteção ao trabalhador que é o mais importante dos princípios da doutrina trabalhista com suas subdivisões.

$\mathrm{Na}$ última seção, serão abordados aspectos específicos da hipossuficiência do trabalhador, sendo destacado, principalmente, o fato de que existe mais de um tipo de vulnerabilidade, a qual não se restringe à hipossuficiência econômica.

\section{FUNÇÃO SOCIAL DA EMPRESA}

Inicialmente, para melhor entendimento do instituto da função social da empresa, deve-se explanar que ela decorre do princípio função social da propriedade, conforme leciona João Luis Nogueira Matias (2009, p. 79), para quem "A função social da empresa é corolário da função social da propriedade, imperativo que decorre da ordem jurídica do mercado, moldada pelo princípio da solidariedade, o que exclui o exercício da atividade empresarial, sem as ponderações que dela decorrem".

Corroborando o entendimento citado, Fábio Ricardo Rodrigues Brasilino (2015, p. 228) assinala: "No ordenamento pátrio, o princípio da função social da 
empresa decorre da função social da propriedade prescrita nos arts. 5ำ XXII, 182, parágrafo $2^{\circ}$, e 186 da CF.".

Assim, cumpre esclarecer, em primeiro lugar, o que é a função social da propriedade, para, logo após, estudar a função social da empresa.

\subsection{FUNÇÃO SOCIAL DA PROPRIEDADE}

É relevante destacar a ideia de que a propriedade, nem sempre, teve a mesma acepção dos dias atuais. Em Roma, o direito à propriedade privada era absoluto. Já na Idade Média surgiu a noção de propriedade horizontal. Nesse passo, relata Luiz Edson Fachin:

\footnotetext{
A propriedade, em Roma, constituiu direito absoluto e perpétuo, excluindose a possibilidade em exercitá-la vários titulares. A Idade Média, por seu turno, consagrou a superposição de propriedades diversas incidindo sobre um único bem, e a Revolução Francesa instaurou o individualismo e o liberalismo. (1988, p. 15).
}

Assim, percebe-se que o direito à propriedade privada evoluiu e sofreu diversas modificações. O direito à propriedade privada, há muito tempo, deixou de ser absoluto, conforme aduz Gustavo Tepedino (1997, p. 321): “A propriedade, portanto, não seria mais aquela atribuição de poder tendencialmente plena, cujos confins são definidos externamente [...]."

Nesse sentido, Otavio Luiz Rodrigues Junior (2012, p. 83) aduz: "O direito fundamental a propriedade não é absoluto. Ele se pauta, como todos os direitos dessa espécie, por restrições, limitações e intervenções.”. Em consonância com o afirmado por Otavio Luiz Rodrigues Junior, Bessone (1996, p. 59) assevera ser importante frisar que o direito de propriedade, do mesmo modo que os demais direitos subjetivos, deve ser considerado de maneira relativa, ou seja, não é um direito absoluto.

Deve-se deixar claro, entretanto que a função social da propriedade não estabelece o fim da propriedade privada. Assim, Melhim Namem Chalhub (2003, p. 308) propala: "A qualificação da propriedade pela sua função social não implica 
supressão dos poderes inerentes à propriedade, nem importa em negação da propriedade privada [...]".

Com efeito, entende-se que a propriedade deve cumprir com um fim social, não sendo plenamente livre seu uso e gozo. Desse modo, Carlos Octaviano de M. Mangueira acentua:

É nesse sentido que incide o princípio da função social da propriedade: estabelecendo ao proprietário, além do poder de usar e dispor do bem, podendo reivindica-lo de quem quer que injustamente o detenha, a obrigação de agir de determinada maneira, positivamente, a fim de cumprir a função social de sua propriedade, justificando e legitimando o próprio direito por meio desse comportamento. (2000, p. 231).

A função social da propriedade não dever ser divisada somente como uma mera limitação ao direito de propriedade, uma vez que, conforme exposto por Fábio Konder Comparato (1995, p.32), ela corresponde a um poder-dever do proprietário, sendo sancionável pela ordem jurídica brasileira.

Nesse sentido, Gilberto Bercovici (2005, p. 147) assinala que: "A função social é mais que uma limitação. Trata-se de uma concepção que consubstancia-se no fundamento, razão e justificação da propriedade".

Assim, extrai-se dos pensamentos citados a ideia de que a função social da propriedade vai além da mera limitação ao exercício do direito de propriedade, sendo, verdadeiramente, um poder-dever do titular do direito.

Além disso, é interessante ressaltar que o limite ao direito de propriedade é baseado nos interesses da sociedade. Assim, ensina Tiago Fensterseifer que:

O exercício do direito de propriedade encontra o seu limite e o seu conteúdo material no equilíbrio das relações sociais. Quando verificada a incompatibilidade da utilização da propriedade individual frente ao interesse social, o segundo deve prevalecer. Esta é a essência do princípio e do direito fundamental da função social da propriedade. (2005, p. 16).

Seguindo o mesmo raciocínio, Tiago Nunes da Silva e Mariana Ribeiro Santiago (2017, p. 40) lecionam que a função social da propriedade exige que o proprietário a utilize do melhor modo, de acordo com os interesses sociais.

Evidencia-se, ainda, o fato de que a propriedade não cumpridora de sua função social não deverá existir para o Direito, conforme leciona Eros Roberto Grau 
(1990, p. 316): "A propriedade dotada de função social, que não esteja a cumpri-la, já não será mais objeto de proteção jurídica. Ou seja, já não haverá mais fundamento jurídico a atribuir direito de propriedade ao titular do bem (propriedade) que não está a cumprir sua função social".

Dessa maneira, infere-se que o cumprimento da função social da propriedade está diretamente relacionado com a observância aos interesses da sociedade. Essa também é a visão que a grande maioria os aplicadores do Direito Brasileiro têm relativamente à função social da empresa, devendo essa relacionar-se com a sociedade e com aqueles que a compõe, especialmente com os empregados.

Assim, em razão da importância de relacionar a função social da empresa com a proteção aos trabalhadores, no tópico seguinte, será feita uma análise da função social voltada para as relações de trabalho.

\subsection{A FUNÇÃO SOCIAL DA EMPRESA COM ÊNFASE NAS RELAÇÕES TRABALHISTAS}

Conforme relatado no tópico anterior, a função social da empresa decorre da função da propriedade, de tal modo que as duas são bastante semelhantes. Assim é interessante destacar a visão de alguns juristas acerca da função social da empresa propriamente dita.

Tomasevicius Filho (2014, p. 142-143) assinala que a percepção sobre o conceito de função social da empresa, entre os aplicadores do Direito, ressoou em profundas mudanças relativas ao tratamento jurídico concedido à atividade empresarial. $\mathrm{O}$ autor salienta ainda que que a principal mudança foi quanto à ideia de que a empresa não seria somente uma modalidade de produção de riquezas e de lucros para seus sócios, mas também a maneira de fornecer empregos aos membros da sociedade. Destaca, por fim, a ideia de que a sociedade empresária cumpre relevante função social, uma vez que, a com suporte nela, são gerados empregos e os cidadãos podem prover o próprio sustento.

Nesse sentido, deve-se salientar o exposto por Guevara Sulpicio (1959, p. 468): "So, some men are beginning to realize that private corporations are not strictly 
private, that they do not exist solely for their own benefit, but that they are deemed legitimate members of an organic society in which they move about."1

Percebe-se, desse modo, que a própria concepção de empresa foi modificada, com a procedência em uma visão mais social da companhia, não sendo considerados, apenas, os interesses societários para efetivar da função social da empresa.

Deve-se compreender, portanto, qual o conceito de função social da empresa, o qual nas palavras de Carlos Aurélio Mota de Sousa (2013, p. 71) é o seguinte: "O conceito de função social não implica em assistencialismo, filantropia ou atividade subsidiária das empresas. Objetivamente, é uma obrigação legal, decorrente da Constituição Federal, sobretudo dos princípios contidos no capítulo de ordem econômica e financeira.”. Nesse ponto, é relevante apontar também a visão de João Luis Nogueira Matias acerca do tema:

[...] pode-se entender a função social da empresa como a vinculação do exercício da empresa à concretização de uma sociedade livre, justa e solidária, do que decorre um complexo de deveres e obrigações, positivas e negativas, impostas aos controladores e administradores, perante os empregados, fornecedores, consumidores, meio ambiente, Estado, e toda a comunidade que com ela interage. (2009, p. 87).

Assim, é compreensível que a função social da empresa, do mesmo modo que o mister da propriedade, relaciona-se diretamente com os interesses sociais, ou seja, o exercício da atividade empresarial deve estar alinhado não só aos interesses dos sócios, mas também aos da comunidade e dos colaboradores que a compõem.

Nesse sentido, Fábio Ricardo Rodrigues Brasilino (2015, p. 228) assevera: "Assim, as sociedades empresarias têm uma função social, a qual interessa aos empregados, fornecedores, à comunidade local e até mesmo ao próprio Estado.”.

Como se observa, o princípio da função social da empresa é plenamente aplicável às relações de trabalho, podendo ser visto como um limitador do poder diretivo do empregador. Sendo compreensível, desse modo, que o poder de direção da empresa do empregador não é absoluto, uma vez que o exercício da função

\footnotetext{
1 Tradução livre: "Então, alguns homens estão começando a perceber que a corporação privada não é estritamente privada, que ela não existe apenas para benefício próprio, mas que são consideradas membros legítimos de uma sociedade orgânica em que atuam.".
} 
empresária deve estar em consonância com os interesses da comunidade e também com os princípios constitucionais.

Corroborando os entendimentos citados, Alexandre Aga Belmonte leciona:

Assim, o poder diretivo permite o exercício patronal da propriedade privada, devendo, portanto, ser exercido nos limites de sua função social: a utilização deve ser feita com respeito às finalidades econômicas e sociais, não podendo ferir a dignidade do trabalhador e o meio ambiente de trabalho. (2004, p. 538).

Insta sobrelevar a conclusão de Mariana Ribeiro Santiago e Elisângela Aparecida de Medeiros (2017, p. 112), as quais referem que "Em suma, trata-se de pensar a função social da empresa como um canal da socialidade, ou seja, as corporações não podem e nem devem causar prejuízos para a sociedade. $O$ interesse das empresas não pode se sobrepor ao da coletividade.".

Além disso, é válido evidenciar ainda que o exercício da atividade econômica e a função social da empresa encontram respaldo na Constituição Federal de 1988, especialmente nos artigos $1^{\circ}, 3^{\circ}$ e 170 , os quais preveem valores como os do desenvolvimento nacional e o da livre iniciativa. Assim, Viviane Perez (2006, p. 144) entende ser: "[...] no texto constitucional que o interprete deverá perquirir os valores que certa sociedade deseja ver cumpridos através do exercício de determinado direito; ou seja: a função social que esta sociedade lhe busca imprimir.".

De acordo com o entendimento de João Luis Nogueira Matias (2009, p.15) os princípios constitucionais definem os padrões para o bom exercício da empresa e da atividade econômica, ressaltando que o mercado deve resguardar à sociedade uma vida digna. O autor cita ainda como exemplo os artigos $1^{\circ}$, $3^{\circ}$ e 170 da Constituição Federal de 1988, há instantes mencionados também.

Nessa perspectiva, Eduardo Secchi Munhoz ensina que,

Nesse sentido, o modelo societário brasileiro deve necessariamente se orientar à consecução dos valores consagrados pela Constituição Federal, ao disciplinar o exercício da atividade empresarial, não se preocupando com as questões de índole exclusivamente privada. (2007, p. 29). 
Seguindo o mesmo raciocínio, Alenilton da Silva Cardoso (2010, p. 15) assinala, ainda, que o caput do artigo 170 da Carta Magna, ao prever valores como a dignidade da pessoa humana, a justiça social e a valorização social do trabalho, confirmou uma ordem finalística à livre iniciativa, a qual há de ser observada pelas empresas, como cumprimento da função social.

Assim, expõe João Luis Nogueira Matias (2009, p. 87): "Trata-se, assim, de um princípio jurídico, que pode ter sua efetividade exigida, não mera proposição de cunho moral. O sentimento de que sua eficácia é vinculada à vontade dos componentes da empresa é um entrave à sua concretização".

Desse modo, é notória a grande importância que tem de ser conferida à função social da empresa, uma vez que ela decorre de previsão constitucional e, de tal maneira, é vista como princípio jurídico constitucional. Devendo, pois, ser aplicada em todas as relações empresariais, especialmente nas relações entre patrões e empregados.

O descumprimento de normas trabalhistas ou o abuso de poder do empregador vai contra o interesse da sociedade e, consequentemente, oposto a diversos princípios constitucionais e trabalhistas, entres eles, destacam-se o princípio da função social da empresa e o da proteção ao trabalhador, que será analisado na seção seguinte.

\section{O DIREITO DO TRABALHO E O PRINCÍPIO DA PROTEÇÃO AO TRABALHADOR}

É necessário, inicialmente, estudar ainda que brevemente, a história do Direito do Trabalho, uma vez que, compreendendo sua origem, restará facilitado o entendimento quanto ao princípio da proteção ao trabalhador e, especialmente, no tocante à sua hipossuficiência.

O Direito do Trabalho surgiu logo após a Revolução Industrial ocorrida na Inglaterra durante o século XVIII. Ives Granda da Silva Martins Filho (2002, p. 13) explica que: "o Direito do Trabalho surgiu, assim, da luta dos trabalhadores pelo reconhecimento da dignidade do trabalho humano, das condições em que se deve 
desenvolver e o que lhe corresponde em termos de retribuição pelo esforço produtivo".

Na Revolução Industrial, os trabalhadores buscavam, justamente, preservar a dignidade humana nas relações de trabalho e combater a exploração e as condições laborais desumanas, conforme exposto por Amauri Mascaro do Nascimento:

O direito do trabalho surgiu como consequência da questão social que foi precedida pela Revolução Industrial do século XVIII e da reação humanista que se propôs a garantir ou preservar a dignidade do ser humano ocupado no trabalho das indústrias, que, com o desenvolvimento da ciência, deram nova fisionomia ao processo de produção de bens na Europa e em outros continentes. A necessidade de dotar a ordem jurídica de uma disciplina para reger as relações individuais e coletivas de trabalho cresceu no envolvimento das "coisas novas" e das "ideias novas", como passamos a mostrar. (2011, p. 33)

Maurício Godinho Delgado (2012, p. 83) leciona: "O Direito do Trabalho é, pois, produto cultural do século XIX e das transformações econômico-sociais e políticas ali vivenciadas. Transformações todas que colocam a relação de trabalho subordinado como núcleo motor do processo produtivo característico daquela sociedade.".

Nessa esteira, Américo Plá Rodriguez (2000, p. 66) alcança a ideia de que: "[...] o Direito do Trabalho surge como consequência de uma desigualdade: a decorrente da inferioridade econômica do trabalhador. Essa é a origem da questão social e do Direito do Trabalho.".

Assim, nota-se que tal especialidade jurídica surge da luta dos empregados contra a exploração feita pelos empregadores, ou seja, de um lado fraco, hipossuficiente, contra um lado mais forte. Essa origem interfere diretamente nos princípios e fundamentos que norteiam o Direito Laboral, sendo este eminentemente protetor e tendo como um dos mais importantes princípios, o da proteção.

\subsection{O PRINCÍPIO DA PROTEÇÃO E SEUS DESDOBRAMENTOS}

O princípio da proteção ao trabalhador relaciona-se diretamente com 0 surgimento do Direito do Trabalho e com as lutas sociais que os antecederam. Esse 
princípio é necessário para tentar igualar as partes da relação contratual trabalhista, uma vez que é claro que o empregado é a parte hipossuficiente da demanda. Assim, aduzem Francisco Ferreira Jorge Neto e Jouberto de Quadros Pessoa Cavalcante (2011, p.17): "O escopo do princípio protetor é atenuar a desigualdade entre o trabalhador e o empregador, o que vem a justificar a existência do Direito do Trabalho.".

Nesse sentido, Vólia Bonfim Cassar (2016, p.170) compreende que: "No Direito do Trabalho há uma desigualdade natural, pois o capital possui toda a força do poder econômico. Desta forma, a igualdade preconizada pelo Direito do Trabalho é tratar os desiguais de forma desigual.".

$\mathrm{Na}$ lição de Ives Gandra da Silva Martins Filho (2002, p. 10), "enquanto no Direito Civil assegura-se a igualdade jurídica dos contratantes, no Direito do Trabalho a preocupação é proteger a parte economicamente mais fraca visando-se alcançar uma igualdade substancial".

Nessa mesma linha de raciocínio, aduz Maurício Godinho Delgado:

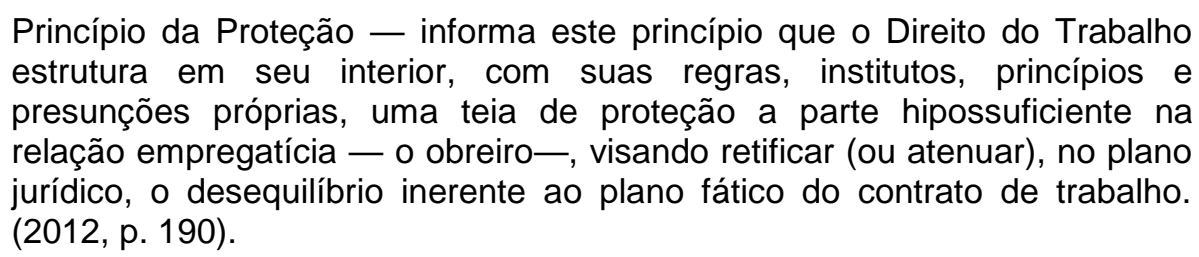

O princípio da proteção ao trabalhador é subdividido em três: do in dubio pro operario, da norma mais favorável e da condição mais benéfica, conforme leciona Américo Plá Rodriguez (2000, p. 107).

Desse modo, serão analisadas as três subdivisões do princípio da proteção expressas por Américo Plá Rodriguez. A primeira subdivisão estudada será a do princípio in dúbio pro operário. Nesse sentido, Augusto César Leite de Carvalho expõe:

Sobre a regra in dubio pro operario, devemos frisar que se trata de técnica de interpretação: quando a norma permite interpretação dúbia ou mais de uma interpretação, deve prevalecer aquela que aproveita ao trabalhador. É importante relembrar que o direito do trabalho surgiu como uma técnica de proteção ao obreiro que, por ser economicamente hipossuficiente, estava por ajustar condições indignas de trabalho, aviltantes para o ser humano. 


\begin{abstract}
Em princípio, toda norma trabalhista parte desse mesmo pressuposto e, se mais de um sentido lhe couber, é de preferir-se aquele que justifica a sua existência, ou seja, privilegia-se a exegese que se mostra apta a oferecer uma condição mais justa de trabalho. (2011, p. 57).
\end{abstract}

Assim, ressalta evidente o fato de que ao interpretar uma norma, o magistrado deverá fazê-lo da forma mais benéfica ao trabalhador.

O princípio da norma mais favorável institui a ideia de que deve ser aplicada a norma mais favorável ao trabalhador, independentemente de sua hierarquia. Apesar, no entanto, da existência desse princípio, desde novembro de 2017, a partir da entrada em vigor da Lei 13.467 de 2017, também conhecida como "Reforma Trabalhista", o legislador brasileiro, especificamente no artigo 620 da Consolidação das Leis do Trabalho², optou por estipular que as condições previstas em Acordo Coletivo, em qualquer situação, prevalecerão sobre as normas da Convenção Coletiva de Trabalho. Assim, percebe-se que houve uma relativização desse princípio, a partir da entrada em vigor da Reforma Trabalhista.

A terceira subdivisão recai no princípio da condição mais benéfica ou princípio da cláusula mais vantajosa, pois garante ao trabalhador que, no curso do contrato de trabalho, as normais benéficas previstas no pacto laboral ou no regulamento da empresa incorporarão ao contrato de trabalho. Com efeito, explica Leone Pereira:

\begin{abstract}
O princípio da condição mais benéfica, também conhecido como princípio da cláusula mais vantajosa, aduz que as condições mais benéficas previstas no contrato de trabalho ou no regulamento da empresa prevalecerão, serão incorporadas definitivamente ao contrato de trabalho, não podendo ser suprimidas ou reduzidas no curso da relação empregatícia. (2012, p. 35).
\end{abstract}

O mesmo autor (2012, p. 36) expõe ainda: "Com efeito, ainda que haja a superveniência de diploma normativo menos protetivo, ele não atinge os contratos de trabalho já existentes, mas apenas os novos contratos.".

Assim, nota-se que diversos princípios do Direito do Trabalho visam a proteção do trabalhador, justamente por ele ser considerado a parte mais frágil da

\footnotetext{
${ }^{2}$ Art. 620. As condições estabelecidas em acordo coletivo de trabalho sempre prevalecerão sobre as estipuladas em convenção coletiva de trabalho.
} 
relação contratual. Verifica-se, no entanto, que esses princípios, por vezes, são relativizados.

Nesse sentido, Sebastião Geraldo de Oliveira (2010, p.47) leciona: "Não se ignora que nos dias atuais o princípio da proteção vem sofrendo abalos sucessivos, em razão do propósito explícito dos empregadores de flexibilizar as normas trabalhistas, postulando alguns até mesmo ampla desregulamentação.".

De efeito, impende se reforçar o entendimento de que, sendo o empregado a parte hipossuficiente da relação de emprego, as normas protetivas não podem ser diminuídas, pois, dessa maneira, aumenta-se ainda mais a disparidade entre o patrão e o empregado.

\section{A HIPOSSUFICIÊNCIA DO TRABALHADOR}

A hipossuficiência do trabalhador nas relações empregatícias é algo notório, tanto que, conforme demonstrado no seguimento imediatamente anterior, existem diversos princípios trabalhistas que pretendem reduzir as desigualdades entre 0 patrão e o empregado. Nessa esteira, aduz Leandro do Amaral D. de Dorneles (2013, p. 293 e 294):

\footnotetext{
A literatura juslaboral clássica e mesmo a contemporânea encontram na hipossuficiência a justificativa dos princípios fundamentais do direito do trabalho - a proteção do empregado e a promoção da melhoria da condição social dos trabalhadores. Em sua concepção técnica originária, hoje um tanto esquecida, a hipossuficiência nos remete fundamentalmente à flagrante desigualdade econômica entre o trabalhador e seu empregador.
}

Cumpre evidenciar, todavia, que a hipossuficiência do trabalhador não se relaciona somente ao fato de que o a condição financeira do empregador é substancialmente melhor do que a do empregado. Nesses casos, tem-se a hipossuficiência econômica, mas, não é só, existem diversos outros tipos de hipossuficiência, como será demonstrado na sequência.

Nesse aspecto, é interessante destacar a visão de Jorge Cavalcanti Boucinhas Filho (2013, p. 920): 


\begin{abstract}
Esquecem-se, porém, que a hipossuficiência em questão é um conceito jurídico e não meramente econômico. Ela é fruto da subordinação que nada é mais do que a sujeição espontânea, ainda que muitas vezes justificadas por uma premente necessidade econômica, do empregado ao poder diretivo do empregador.
\end{abstract}

A hipossuficiência é, muitas vezes, vista somente, pelo seu viés econômico, ou seja, sendo considerado hipossuficiente aquele de parcos recursos econômicos. No entanto, é necessário esclarecer, entretanto que, atualmente, se estudam outras espécies de hipossuficiência, as quais serão analisadas aqui.

Nesse sentido, Leandro do Amaral D. de Dorneles (2013, p. 295) ensina que no plano do Direito do Trabalho, nas relações laborais, são facilmente identificáveis diversos tipos de hipossuficiências e ele menciona como exemplos a econômica e a técnica.

Em consonância com os entendimentos citados, Paulo Gustavo de Amarante Merçon (2010, p. 139) garante que: "A hipossuficiência na relação jurídica irá afetar a pessoa do trabalhador de diversos modos, desde a constrição de sua vontade até a posição vulnerável na negociação do contrato e exigência de seu cumprimento."

A primeira a ser estudada é a hipossuficiência econômica. Esse é o tipo mais conhecido, sendo considerado, nesse aspecto, a condição econômica do empregado, que é pior do que a do empregador, na grande maioria das vezes. Diversas vezes, há uma dependência econômica do trabalhador em relação ao seu tomador. Nesse sentido, Vólia Bonfim Cassar (2016, p. 170) relata que o empregado já inicia a relação trabalhista em situação desigual à do empregador, sendo um dos motivos a hipossuficiência econômica.

Nas palavras de Paulo Gustavo de Amarante Merçon (2010, p. 138): "A desigualdade econômica que desfavorece o trabalhador na relação de trabalho decorre de sua carência de meios, naquela relação, para produzir (bens ou serviços) para o mercado de consumo.".

Essa hipossuficiência econômica era naturalmente presumida também no processo do trabalho, tanto que a justiça gratuita era concedida sem questionamentos aos reclamantes, independentemente das condições financeiras do mesmo. 
Desde o dia 11 de novembro de 2017, contudo, com a entrada em vigor da "Reforma Trabalhista", os reclamantes poderão ser condenados ao pagamento de custas processuais e de honorários periciais, como previsto no artigo $790-\mathrm{B}^{3}$ da CLT, por exemplo.

A segunda hipossuficiência é de teor técnico. Esse tipo de hipossuficiência advém do fato de o empregado não possuir muitos conhecimentos específicos acerca de seu contrato de trabalho e nem de seus direitos. Assim, em determinadas situações, os empregados podem deixar de receber determinado benefício, simplesmente pela falta de conhecimento.

Rogério de Oliveira Souza (2004, p. 92) conceitua a hipossuficiência técnica: "A hipossuficiência de informação (técnica) volta-se para as próprias condições pessoais da parte que não avalia o que seja relevante para a defesa de seus interesses, não compreendendo o valor deste ou daquele documento [...]".

Nesse ponto, é interessante fazer um paralelo com o Direito do Consumidor. Nas relações consumeristas, o consumidor é considerado a parte hipossuficiente do contrato. Assim, destaca-se o entendimento de Cláudia Lima Marques acerca do tema:

\footnotetext{
$\mathrm{Na}$ vulnerabilidade técnica, o comprador não possui conhecimentos específicos sobre o objeto que está adquirindo e, portanto, é mais facilmente enganado quanto às características do bem ou quanto à sua utilidade, o mesmo ocorrendo em matéria de serviços. Será presumida para - consumidor não profissional, podendo atingir excepcionalmente 0 profissional destinatário final fático do bem. (2002, p.84).
}

É necessário ressaltar que, em alguns, não existirá a hipossuficiência técnica, como é o caso de profissionais que exercem elevados cargos ou que tem bastante conhecimento sobre o exercício de sua função. É possível, entretanto, que o empregado não seja hipossuficiente tecnicamente, mas seja hipossuficiente financeiramente.

A terceira e última espécie é a hipossuficiência negocial. Esse tipo é um dos mais evidentes, pois remete ao acentuado desequilíbrio contratual entre as partes,

\footnotetext{
${ }^{3}$ Art. 790-B. A responsabilidade pelo pagamento dos honorários periciais é da parte sucumbente na pretensão objeto da perícia, ainda que beneficiária da justiça gratuita.
} 
uma vez que, salvo raríssimas exceções, o empregado poderá alterar livremente qualquer cláusula do contrato de trabalho que não considere interessante.

Esse tipo de hipossuficiência é facilmente verificado, principalmente, em contratos de trabalho com empregados menos especializados. No entanto, em contratos realizados com funcionários mais especializados, com o poder maior de barganha, é possível que haja negociação e até maiores benefícios a esses empregados do que os demais.

Assim, conclui-se que a hipossuficiência do trabalhador sempre existirá nas relações trabalhistas, uma vez que o conceito de hipossuficiente não está restrito a apenas uma espécie de vulnerabilidade.

De tal maneira, entende-se que a função social da empresa, conforme já amplamente exposto anteriormente, deve abarcar também a proteção ao trabalhador e garantir que os direitos e interesses da coletividade e dos colaboradores que compõem a companhia sejam respeitados.

\section{CONCLUSÃO}

Em linhas gerais, pode-se concluir, inicialmente, que a função social da empresa é um princípio jurídico que deriva da função social da propriedade. Desse modo, se alcança o argumento de que o empresário, para atender aos fundamentos da função social da empresa, deve alinhar os interesses da sociedade empresária aos da sociedade como um todo, em especial com os de seus funcionários.

No tocante ao Direito do Trabalho, registra-se o fato de que ele emergiu das lutas do proletariado contra as péssimas condições de trabalho as quais eram submetidos. Assim, entende-se que o direito laboral tem em sua essência o combate às desigualdades naturais advindas da relação de trabalho.

Nesse sentido, é imperioso destacar o princípio mais importante do Direito do Trabalho, o princípio da proteção ao trabalhador, o qual é subdividido em: princípio da norma mais favorável, princípio da condição mais benéfica e princípio in dubio pro operario. 
De modo geral, como do próprio nome se extrai, o princípio da proteção e seus subprincípios visam a diminuir as desigualdades da relação entre patrão e empregado, protegendo a parte hipossuficiente, no caso o trabalhador.

No tocante à hipossuficiência do trabalhador, tem-se que existem diversos tipos de hipossuficiência. No entanto, muitas vezes, apenas a hipossuficiência econômica é observada. Assim, é necessário demonstrar que além da hipossuficiência econômica, pode-se falar também em hipossuficiência técnica e em hipossuficiência negocial.

A hipossuficiência técnica ou de informação existe quando o empregado não tem conhecimento suficiente sobre seus direitos. Nesse ponto, é possível fazer um paralelo com o Direito do Consumidor, em que o consumidor, parte hipossuficiente da relação, não tem conhecimento técnico, na maioria das vezes, do produto ou serviço que adquiriu, devendo ser protegido pelas normas consumeristas e também pelo princípio da função social da empresa.

A hipossuficiência negocial diz respeito ao fato de que os empregados, normalmente, não têm poder de barganha ao celebrar um contrato de trabalho. Comumente, o empregado, apenas aceita as disposições previstas no contrato afim de garantir sua sobrevivência.

Desse modo, conclui-se que a função social da empresa pode e deve ser utilizada como mais um fundamento para a proteção do trabalhador, seja pelo fato de o empregado ser hipossuficiente ou porque a empresa, ao cumprir com sua função social, deve observar os interesses de seus empregados e da sociedade.

\section{REFERÊNCIAS}

BELMONTE, Alexandre Agra. Institutos Civis no Direito do Trabalho. 3. ed. Rio de Janeiro: Renovar, 2004.

BERCOVICI, Gilberto. Constituição econômica e desenvolvimento - uma leitura a partir da Constituição de 1988. São Paulo: Malheiros, 2005.

BESSONE, Darcy. Direitos Reais. 2.ed. São Paulo: Saraiva, 1996.

BRASILINO, Fábio Ricardo Rodrigues. Função social e preservação da empresa: a teoria da desconsideração da personalidade positiva como instrumento efetivador. 
Revista de Direito Privado. São Paulo: Revista dos Tribunais, 07/2015 a 09/2015 v.16 n.63. pp. 221 a 235.

BOUCINHAS FILHO, Jorge Cavalcanti. O Alto executivo e a proteção do direito do trabalho. Revista LTR: Revista Legislação do Trabalho. São Paulo: Ltr, 08/2013. pp. 914 a 92 . v.77 n.8.

CARDOSO, Alenilton da Silva. A funcionalização social do direito privado. Revista Forense: doutrina, legislação e jurisprudência. Rio de janeiro: Forense, 05/2010 a 06/2010. v.409.pp. 3-26.

CARVALHO, Augusto César Leite de. Direito do Trabalho: curso e discurso. Aracaju: Evocati, 2011.

CASSAR, Vólia Bomfim. Direito do Trabalho. 12. ed. Rio de Janeiro: Forense, 2016.

CHALHUB, Melhim Namem. Função Social da Propriedade. Revista da EMERJ, v. 6, n. 24, pp. 305-317, $2003 . \quad$ Disponível em: < http://www.emerj.tjri.jus.br/revistaemerj online/edicoes/revista24/revista24 305.pdf > Acesso em 9 jan. 18

COMPARATO, Fábio Konder. Direito Empresarial: estudos e pareceres. São Paulo: Saraiva, 1995.

DELGADO, Maurício Godinho. Curso de Direito do Trabalho. 11. ed. São Paulo: LTr, 2012.

DORNELES, Leandro do Amaral D. de. Hipossuficiência e vulnerabilidade na teoria geral do direito do trabalho contemporânea. Revista LTR: Revista Legislação do Trabalho. São Paulo: Ltr, 03/2013. v.77 n.3. pp. 293 a 303.

FACHIN, Luiz Edson. A função social da posse e a propriedade contemporânea. Porto Alegre: Sérgio Fabris Editor, 1988.

FENSTERSEIFER, Tiago. A função social como elemento constitutivo do núcleo normativo-axiológico do direito de (à) propriedade - uma leitura comprometida com a realidade social brasileira. Revista da Faculdade de Direito UFPR. V. 43, N. 0. 2005. Disponível em: < http://revistas.ufpr.br/direito/article/view/7059 > Acesso em: 07 jul 2017

GRAU, Eros Roberto. A ordem econômica na Constituição de 1988 interpretação e crítica. São Paulo: Revista dos Tribunais, 1990.

JORGE NETO, Francisco Ferreira; CAVALCANTE, Jouberto de Quadros Pessoa. Curso de Direito do Trabalho. 2.ed. São Paulo: Atlas, 2011. 
MANGUEIRA, Carlos Octaviano de M. Função social da propriedade e proteção ao meio ambiente: notas sobre os espaços protegidos nos imóveis rurais. Revista de informação legislativa, v. 37, n. 146, pp. 229-249, abr./jun. 2000. Disponível em: < http://www2.senado.leg.br/bdsf/item/id/594 > Acesso em 09 jan. 18

MATIAS, João Luis Nogueira. A função social da empresa e a composição de interesses na sociedade limitada. 2009. 282 f. Tese (doutorado em Direito Comercial) - Universidade de São Paulo (USP), São Paulo, 2009. Disponível em: < http://www.teses.usp.br/teses/disponiveis/2/2132/tde-06052010-140746/pt-br.php > Acesso em: 30 maio 2017.

MARTINS FILHO, Ives Gandra da Silva. Manual esquemático de direito e processo do trabalho.10. ed. São Paulo : Saraiva, 2002.

MARQUES, Cláudia Lima. Contratos no código de defesa do consumidor. 4. ed. São Paulo: RT, 2002.

MERÇON, Paulo Gustavo de Amarante. Direito do Trabalho Novo. Rev. Trib. Reg. Trab. 3a Reg., Belo Horizonte, v.51, n.81, p.137-154, jan./jun.2010. Disponível em < http://www.trt3.jus.br/escola/download/revista/rev 81/paulo gustavo mercon.pdf > Acesso em: 29 set 2017.

MUNHOZ, Eduardo Secchi. Empresa contemporânea e Direito Societário - poder de controle e grupos de sociedades. São Paulo: Juarez de Oliveira, 2007.

NASCIMENTO, Amauri Mascaro do. Curso de direito do trabalho: História e Teoria Geral do Direito do Trabalho: Relações Individuais e Coletivas do Trabalho. 26. ed. São Paulo: Saraiva, 2011.

OLIVEIRA, Sebastião Geraldo de. Proteção jurídica à saúde o trabalhador. 5. ed. São Paulo: LTr, 2010.

PEREIRA, Leone. Direito do Trabalho. São Paulo: LTR, 2012.

PEREZ, Viviane. Função social da empresa. Revista de Direito do Estado. v.1 n.4.10/2006-12/2006. pp. 141 a 171, Rio de Janeiro: Renovar ,2006.

RODRIGUEZ, Américo Plá. Princípios de Direito do Trabalho. 3. ed. São Paulo: LTR, 2000.

RODRIGUES JUNIOR, Otavio Luiz . Propriedade e função social: Exame crítico de um caso de "constitucionalização" do Direito Civil. In: VERA-CRUZ PINTO, Eduardo; SOUSA, Marcelo Rebelo de; QUADROS, Fausto de; OTERO, Paulo.. (Org.). Estudos de Homenagem ao Prof. Doutor Jorge Miranda: Volume 3 - Direito Constitucional e Justiça Constitucional. 1. ed.Coimbra: Coimbra Editora, 2012, v. 3, p. 61-90.

SANTIAGO, Mariana Ribeiro; MEDEIROS, Elisângela Aparecida de. Função social e solidária da empresa: impactos na liberdade econômica versus benefícios no 
desenvolvimento nacional. Revista Jurídica, vol. 02, n. 47, pp. 99-122, Curitiba, 2017. Disponível em: http://revista.unicuritiba.edu.br/index.php/RevJur/article/view/2028/1307 > Acesso em 18 jul. 18

SILVA, Tiago Nunes da; SANTIAGO, Mariana Ribeiro. Função social/solidária da empresa: a atuação da empresa para o desenvolvimento sustentável sob a ótica ambiental. Revista de Direito Ambiental. São Paulo: Revista Dos Tribunais, 07/2017 a 09/2017. v.22 n.87.p. 37 a 56.

SOUSA, Carlos Aurélio Mota de. Responsabilidade da empresa no aperfeiçoamento dos empregados. Revista Jurídica. v. 1, n. 30, pp. 66-90, Curitiba, 2013. Disponível em: < http://revista.unicuritiba.edu.br/index.php/RevJur/article/view/555 > Acesso em 19 jul. 18.

SOUZA, Rogerio de Oliveira. Da hipossuficiência. Revista da EMERJ. Rio de Janeiro. V. 7. N. 28.pp. 88-98. 2004. Disponível em: < http://www.emerj.tjri.jus.br/revistaemerj online/edicoes/revista28/revista28 88.pdf $>$ Acesso em: 10 jan. 18.

SULPICIO, Guevara. The Social Function of Private Corporations. Philippine Law Journal, Vol. 34, No. 4, pp.464- 472, 1959.

TEPEDINO, Gustavo. Contornos constitucionais da propriedade privada. In: DIREITO, Carlos Alberto Menezes. Estudos em homenagem ao professor Caio Tácito. Rio de Janeiro: Renovar, 1997.

TOMASEVICIUS FILHO, Eduardo. Empreendedorismo e função social da empresa. Revista dos Tribunais. São Paulo: Revista Dos Tribunais, v.103 n.946. 08/2014. p. 129 a 156. 